\title{
Protective effect of the leaves of Vitex negundo against ethanol-induced cerebral oxidative stress in rats
}

\author{
MUTHUSWAMY UMAMAHESWARI ${ }^{*}$ KUPPUSAMY ASOKKUMAR, NANDAGOPI \\ UMAMAGESWARI, THIRUMALAISAMY SIVASHANMUGAM and VARADHARAJAN \\ SUBHADRADEVI \\ Department of Pharmacology, College of Pharmacy, Sri Ramakrishna Institute of Paramedical Sciences, \\ Coimbatore - 641 044, Tamil Nadu, India
}

\begin{abstract}
The present study investigated the effect of the various fractions of hydromethanolic extract of the leaves of Vitex negundo (Verbenaceae) against ethanol-induced cerebral oxidative stress in rats. Cerebral oxidative stress was induced by the administration of $20 \%$ ethanol (5 ml/100gbw) for a period of 28 days. The petroleum ether (PEF), chloroform (CF), ethylacetate (EAF) and residual (RF) fractions at a dose of $200 \mathrm{mg} / \mathrm{kgbw}$ orally were simultaneously administered with ethanol for 28 days. $\alpha$-tocopherol at a dose of $100 \mathrm{mg} / \mathrm{kg}$ orally was used as the standard. Administration of ethanol resulted in a significant elevation in serum biochemical parameters like aspartate transaminase (AST), alanine transaminase (ALT), alkaline phosphatase (ALP), uric acid, triglycerides and lipoprotein levels. In addition there was a significant $(P<0.01)$ elevation in malondialdehyde (MDA) and lipid hydroperoxide $(\mathrm{LH})$ levels and a significant $(P<0.01)$ reduction in enzymatic and non-enzymatic antioxidants in the brain tissue. Histopathological examination of the brain tissue of the ethanol treated animals showed marked gliosis. Simultaneous administration of the fractions prevented the enzymatic leakage and elevation of serum uric acid, triglycerides and lipoprotein levels. All the fractions (except the residual fraction) prevented the rise in lipid peroxidation and enhanced the antioxidant enzymes. Further, histopathological examination revealed that the fractions of $V$. negundo offered a significant protection against ethanol toxicity in rat brain. The activity exhibited by the chloroform fraction is comparable to that of the standard. The present study reveals that the leaf of $V$. negundo has protective action on the brain, which could be attributed to its antioxidant potential.
\end{abstract}

Keywords: Antioxidant enzymes, ethanol, lipid peroxidation, oxidative stress, Vitex negundo

\section{Introduction}

Alcohol is a neurotoxin whose addiction is more complex than other addictions (Scheepers, 1997). Excessive intake of alcohol causes severe damage to the liver, which may become cirrhotic. Ethanol exerts a dose-dependent effect on the central nervous system by crossing the blood-brain barrier, heart and the testes (Charness et al., 1989; Nordmann et al., 1990). Chronic intake of alcohol may produce functional deficits such as psychoses and hallucination in addition to structural alterations such as cortical atrophy (Phillips et al., 1952). Both larger and smaller doses of ethanol taken repeatedly, increases lipid peroxidation in the liver followed by the accumulation of conjugated dienes and decreases the levels of GSH and antioxidant enzymes in liver, brain and kidney cells (Halliwell \& Gutteridge, 1989). Metabolism of ethanol leads to oxidative stress through the generation of reactive oxygen species, which can start lipid peroxidation by exhausting antioxidant substances in the cell thereby changing the balance in favour of increased peroxidation (Dianzani, 1985; Zima et al., 2001). Cells have a number of defense mechanism against free

\footnotetext{
*Correspondence: Dr. Muthuswamy Umamaheswari; E-mail: umasaravanaprakash@gmail.com
} 
radical damage and the problem arises when the production of reactive oxygen species (ROS) exceeds their elimination by antioxidant protective system. The target of oxidative damage of ethanol in brain has been identified as the enzyme glutathione synthetase and neurofilaments, which can be nitrated by ONOO - that leads to the disruption of their organization (Halliwell \& Gutteridge, 1989). The oxidation product of ethanol is acetaldehyde that stimulates lipid peroxidation leading to increased membrane fluidity, disturbance of $\mathrm{Ca}^{2+}$ homeostatis and finally cell death (Nordmann, 1994). Acetaldehyde undergoes reversible reaction with GSH and protein thiol and nitro groups and also reacts with dopamine and serotonin in the brain to form neurotoxic products such as tetrahydroisoquinolines and tetrahydro- $\beta$-carbolines. Recent research has focused on the development of antioxidant drugs that may delay or minimize neurodegeneration (Callaway et al., 1998).

Many herbs and medicinal plants are rich natural sources of antioxidants. Vitex negundo L. belonging to the family Verbenaceae is widely distributed in India. The leaves of the species contain a significant amount of antioxidants such as agnuside, eurostoside, aucubin, flavonoids, casticin and vitexin. The leaves are used in indigenous medicine for the treatment of rheumatic disease, headache, catarrhal fever, cervical spondylitis and body pain (Warrier et al., 1995). The leaves of $V$. negundo has been reported for its anti-inflammatory (Tandon \& Gupta, 2006), analgesic and antihistaminic property (Dharmasiri et al., 2003), snake venom neutralizing capacity (Alam \& Gomes, 2003), hepatoprotective (Avadhoot \& Rana 1991) and CNS depressant activities (Gupta et al., 1999). To our knowledge, there are no available reports on the effect of leaves of $V$. negundo against ethanol-induced cerebral oxidative stress. Hence the objective of the present work is to study the protective effect of the various fractions of $V$. negundo hydromethanolic leaf extract against ethanol-induced cerebral oxidative stress in rats.

\section{Materials and Methods}

\section{Plant material and preparation of extract fractionation}

The leaves were collected from Coimbatore district, Tamil Nadu, India during May 2007. The plant was identified and authenticated by Dr. G.V.S. Murthy, Joint Director, Botanical Survey of India, Tamil Nadu Agricultural University Campus, Coimbatore bearing the reference number BSI/SC/5/23/07-08/Tech.-349.

Fresh leaves of the plant were dried in shade under room temperature, powdered mechanically and sieved through No.20 mesh sieve and extracted with methanol:water (7:3) and the hydromethanolic extract $(27 \%)$ was partitioned separately against petroleum ether, chloroform and ethyl acetate separately in the order of increasing polarity. The petroleum ether fraction (PEF) (2\%), chloroform fraction (CF) $(1.2 \%)$, ethyl acetate fraction (EAF) $(1.4 \%)$ and residual fraction (RF) (21\%) of $V$. negundo were used for the study.

\section{Drugs and chemicals}

Absolute ethanol, vitamin E, 2-2' dipyridyl and O-dianisidine were obtained from Himedia Laboratories Ltd., Mumbai, India. Butylated hydroxyl toluene, oxidized glutathione, epinephrine and 5, 5'-dithiobis-2-nitrobenzoic acid (DTNB) were obtained from Sisco Research Laboratories Pvt., Ltd., Mumbai, India. All other drugs and chemicals used in the study were obtained commercially and were of analytical grade. 


\section{Acute toxicity studies}

Swiss albino mice (20-25 g) maintained under standard laboratory conditions was used. A total of five animals were used which received a single oral dose $(2000 \mathrm{mg} / \mathrm{kg}$, body weight of the fraction. Animals were kept overnight fasting prior to drug administration. After the administration of the fraction, food was withheld for further 3-4 h. Animals were observed individually at least once during the first 30 minutes after dosing, periodically during the first 24 hours (with special attention during the first $4 \mathrm{~h}$ ) and daily thereafter for a period of 14 days. Once daily cage side observations included changes in skin and fur, eyes and mucous membrane (nasal), and also respiratory rate, circulatory (heart rate and blood pressure), autonomic (salivation, lacrimation, perspiration, piloerection, urinary incontinence and defecation) and CNS (ptosis, drowsiness, gait, tremors and convulsions) changes.

\section{Experimental animals and design}

Wistar albino rats of either sex weighing between 150-200 g were used for the study. The animals were housed in polypropylene cages inside a well-ventilated room. The room temperature was maintained at $23 \pm 2^{\circ} \mathrm{C}$ with a $12 \mathrm{~h}$ light / dark cycle. The animals were fed with commercial rat feed pellets and provided with drinking water ad libitum. All animal procedures have been approved by institutional animal ethical committee in accordance with animal experimentation and care.

Cerebral oxidative stress was induced in rats by feeding $20 \%$ ethanol $(5 \mathrm{ml} / 100 \mathrm{gbw})$ for a period of 28 days (Saravanan et al., 2003; Das et al., 2007). Animals were divided into 6 groups consisting of six animals each. Group I received normal saline (10 ml/kgbw, orally) and served as solvent control. Group II received $20 \%$ ethanol $(5 \mathrm{ml} / 100 \mathrm{gbw})$ orally and served as alcohol control. Groups III-VI received petroleum ether (PEF), chloroform (CF), ethyl acetate (EAF) and residual fractions (RF) of $V$. negundo respectively at a dose of 200 $\mathrm{mg} / \mathrm{kgbw}$, orally. Group VII received vitamin E $(100 \mathrm{mg} / \mathrm{kg})$ and served as the standard (Agar et al., 2003). The fractions and the reference drug were suspended in $20 \%$ ethanol and administered for a period of 28 days.

On the $29^{\text {th }}$ day, blood was collected by retro-orbital puncture under mild ether anesthesia. The levels of serum triglycerides (TG), cholesterol, low-density lipoprotein (LDL), very low-density lipoprotein (VLDL) and high- density lipoprotein (HDL), uric acid and serum marker enzymes like aspartate transaminase (AST), alanine transaminase (ALT) and alkaline phosphatase (ALP) were determined using standard kits in a semiautoanalyser. Immediately after blood collection, the animals were sacrificed by cervical dislocation and the brain was removed, homogenized with $0.1 \mathrm{M}$ ice cold phosphate buffer ( $\mathrm{pH} 7.4$ ) and centrifuged at $5000 \mathrm{~g}$ for $10 \mathrm{~min}$ and the resulting supernatant was used for the assay of lipid peroxidation and enzymatic and non enzymatic antioxidants. The amount of total protein present in the tissue was estimated by the method of Lowry et al., 1951. Lipid peroxidation as evidenced by the formation of malondialdehyde (MDA) and lipid hydroperoxides (LH) were measured by the method of Niehaus \& Samuelsson (1968). Superoxide dismutase (SOD) activity was determined by the inhibition of auto catalyzed adrenochrome formation in the presence of the homogenate at $480 \mathrm{~nm}$ (Kakkar et al., 1984). Catalase (CAT) activity was estimated by the catalysis of hydrogen peroxide $\left(\mathrm{H}_{2} \mathrm{O}_{2}\right)$ to water in an incubation mixture adjusted to $\mathrm{pH} 7.0$ and recorded at $254 \mathrm{~nm}$ (Sinha, 1972). Gutathione reductase (GSSH) activity was determined spectrophotometrically by the 
decrease in absorbance of NADPH at $340 \mathrm{~nm}$ (Racker, 1955). Glutathione peroxidase (GPx) activity was measured by the procedure of Paglia \& Valentine (1967). Peroxidase (Px) activity was measured spectrophotometrically by following the change in absorbance at 460 $\mathrm{nm}$ due to $\mathrm{O}$-dianisidine oxidation in the presence of $\mathrm{H}_{2} \mathrm{O}_{2}$ and the enzyme (Lobarzewski \& Ginalska, 1995). The estimation of non-enzymatic antioxidants like reduced glutathione (GSH) and $\alpha$-tocopherol were carried out. The determination of GSH was based on the reaction of reduced glutathione with DTNB to give a compound that absorbs at $412 \mathrm{~nm}$ (Ellman, 1959). The estimation of $\alpha$-tocopherol was carried out by the Emmerie Engel reaction based on the reduction of ferric to ferrous ion by $\alpha$-tocopherol which forms a red coloured complex with 2, 2'-dipyridyl (Baker et al., 1980).

\section{Histopathological studies}

A portion of brain tissue in each group was fixed in 10\% formaldehyde solution, dehydrated in gradually increasing concentrations of ethanol $50-100 \%$, cleared in xylene and embedded in paraffin for histopathological studies. Brain sections of $5 \mu \mathrm{m}$ thickness were prepared. Haemotoxylin and eosin were used for staining and later the microscopic slides of brain cells were photographed.

\section{Statistical analysis}

Statistical analysis of the results was carried out using GraphPad by one-way analysis of variance (ANOVA) followed by Dunnett's test. Results were expressed as mean \pm SEM from six rats in each group. $\mathrm{P}<0.05$ was considered significant.

\section{Results}

In acute toxicity studies, it was found that the animals were safe up to a maximum dose of at $2000 \mathrm{mg} / \mathrm{kgbw}$. There were no changes in normal behavioural pattern and no signs and symptoms of toxicity and mortality were observed. The diet intake of different groups was almost similar. After 28 days of ethanol administration, there was a significant $(P<0.01)$ decrease in the body weight of ethanol-treated rats compared to control (Table 1). There was no significant difference $(P<0.01)$ in the body weight of the animals treated with the various fractions of $V$. negundo and vitamin $\mathrm{E}$ when compared with the control rats. The body weight of normal controls significantly increased by approximately $9.5 \%$ over their basal values after 28 days of treatment, whereas there was a significant $(P<0.01)$ decrease in the body weight of ethanol-treated rats (6\%). Administration of the CF and EAF of $V$. negundo caused a significant weight gain of $3.8 \%$ and $3.5 \%$, respectively, on the 28th day. Treatment with Vitamin E produced 3.2\% increase in weight gain; however, the weight gain of the treated groups remained lower than the normal control.

Animals fed with ethanol showed a significant $(P<0.01)$ increase in the levels of uric acid, triglycerides, cholesterol, LDL and VLDL and a decrease in HDL level. The activities of serum marker enzymes like AST, ALT and ALP were significantly $(P<0.01)$ increased in ethanol-treated rats when compared to control rats. Rats fed simultaneously with ethanol and the PEF, EAF and CF of $V$. negundo showed marked reduction in the levels of serum uric acid, triglycerides, cholesterol, LDL, VLDL and the activities of AST, ALT and ALP and an increase in HDL levels when compared with rats fed only with ethanol. Rats fed 
simultaneously with ethanol and vitamin E showed the serum uric acid, lipid and enzyme levels which was almost similar to the control rats (Tables 1 and 2).

Table 1: Effect of the fractions of $V$. negundo on body weight, serum maker enzymes and uric acid in control and experimental animals

\begin{tabular}{|c|c|c|c|c|c|c|}
\hline \multirow[t]{2}{*}{ Treatment } & \multicolumn{2}{|c|}{ Body weight } & \multirow[t]{2}{*}{$\operatorname{ALP}(u / 1)$} & \multirow[t]{2}{*}{ AST (u/l) } & \multirow[t]{2}{*}{$\operatorname{ALT}(\mathbf{u} / \mathbf{l})$} & \multirow{2}{*}{$\begin{array}{l}\text { Uric acid } \\
\text { (mg/dl) }\end{array}$} \\
\hline & Initial & Final & & & & \\
\hline Normal control & $141.6 \pm 4.7$ & $155 \pm 4.2$ & $899.2 \pm 61.9$ & $972.6 \pm 43.5$ & $307 \pm 56.9$ & $0.2 \pm 0.05$ \\
\hline Alcohol control & $140 \pm 4.4$ & $131.6 \pm 3.8^{*}$ & $5519.6 \pm 95.6^{*}$ & $1809.1 \pm 23.6^{*}$ & $1689 \pm 31.5^{*}$ & $7.1 \pm 0.32^{*}$ \\
\hline PEF & $140 \pm 5.7$ & $139.1 \pm 4.9^{c}$ & $1557.4 \pm 81.0^{\mathrm{b}}$ & $1481.2 \pm 31.6^{\mathrm{b}}$ & $1213.1 \pm 64.7^{b}$ & $3.0 \pm 0.47^{b}$ \\
\hline CF & $131.6 \pm 8.3$ & $136.6 \pm 7.6^{a}$ & $1324.1 \pm 64.3^{\mathrm{b}}$ & $1403.3 \pm 20.8^{b}$ & $367.4 \pm 87.14^{\mathrm{b}}$ & $4.9 \pm 0.65^{\mathrm{b}}$ \\
\hline EAF & $141.6 \pm 12.4$ & $146.6 \pm 12.1^{a}$ & $1684.8 \pm 47.82^{b}$ & $1438.5 \pm 65.45^{b}$ & $568.69 \pm 124.4^{b}$ & $5.6 \pm 0.5^{\mathrm{b}}$ \\
\hline RF & $150 \pm 6.3$ & $147.5 \pm 2.8^{c}$ & $3431.9 \pm 196^{\mathrm{b}}$ & $1640.3 \pm 27.8^{\mathrm{b}}$ & $1550.2 \pm 21.7 \mathrm{c}$ & $2.1 \pm 0.08^{b}$ \\
\hline Vitamin E & $155 \pm 4.2$ & $160 \pm 4.4^{\mathrm{a}}$ & $1139.2 \pm 55.7^{b}$ & $1037.8 \pm 50.0^{\mathrm{b}}$ & $348.3 \pm 25.8^{\mathrm{b}}$ & $1.0 \pm 0.01^{\mathrm{b}}$ \\
\hline
\end{tabular}

AST - Aspartate transaminase; ALT - Alanine transaminase; ALP - Alkaline phosphatase; PEF - Petroleum ether fraction; CF - Chloroform fraction; EAF - Ethylacetate fraction; RF - Residual fraction. Values are expressed as mean $\pm \mathrm{SEM} ; \mathrm{n}=6$; ${ }^{*} \mathrm{P}<0.01$ when compared to normal control; ${ }^{\mathrm{a}} \mathrm{P}<0.01, \mathrm{~b}<0.05$ and $\mathrm{P}>0.05$ when compared to alcohol control (one way ANOVA followed by Dunnett's test)

There was a significant $(P<0.01)$ increase in the concentrations of MDA and LH and a decrease in protein content in the brain tissues of rats fed with ethanol when compared with control rats. Rats administered simultaneously with ethanol and the PEF, EAF and CF of $V$. negundo showed near-normal levels of tissue malondialdehyde, lipid hydroperoxides and protein content similar to vitamin E. Treatment with RF did not show any significant effect $(P>0.05)$ when compared to ethanol control (Table 3).

Table 2: Effect of the fractions of Vitex negundo on serum lipid profile in control and experimental animals

\begin{tabular}{llllll}
\hline Treatment & $\begin{array}{l}\text { Triglycerides } \\
(\mathbf{m g} / \mathbf{d l})\end{array}$ & $\begin{array}{l}\text { Cholesterol } \\
(\mathbf{m g} / \mathbf{d l})\end{array}$ & $\begin{array}{l}\text { HDL } \\
(\mathbf{m g} / \mathbf{d l})\end{array}$ & $\begin{array}{l}\text { LDL } \\
(\mathbf{m g} / \mathbf{d l})\end{array}$ & $\begin{array}{l}\text { VLDL } \\
(\mathbf{m g} / \mathbf{d l})\end{array}$ \\
\hline Normal control & $20.87 \pm 0.57$ & $29.7 \pm 1.57$ & $199.6 \pm 16.6$ & $174.05 \pm 15.8$ & $4.17 \pm 0.11$ \\
Alcohol control & $90.21 \pm 1.06^{\mathrm{a}}$ & $330 \pm 35.3^{\mathrm{a}}$ & $32.48 \pm 4.22 \mathrm{a}$ & $238.2 \pm 37.5^{\mathrm{a}}$ & $18.04 \pm 0.21^{\mathrm{a}}$ \\
PEF & $21.98 \pm 2.48^{\mathrm{b}}$ & $30.09 \pm 2.13^{\mathrm{b}}$ & $73.86 \pm 11.07$ & $52.3 \pm 8.4^{\mathrm{b}}$ & $3.9 \pm 0.49^{\mathrm{b}}$ \\
CF & $25.35 \pm 3.27^{\mathrm{b}}$ & $41.71 \pm 3.72^{\mathrm{b}}$ & $174.08 \pm 24.4 \mathrm{~b}$ & $10.36 \pm 1.9^{\mathrm{b}}$ & $5.07 \pm 0.6^{\mathrm{b}}$ \\
EAF & $40.53 \pm 3.42^{\mathrm{b}}$ & $44.65 \pm 3.54^{\mathrm{b}}$ & $47.12 \pm 6.4$ & $23.07 \pm 3.6^{\mathrm{b}}$ & $8.1 \pm 0.68^{\mathrm{b}}$ \\
RF & $82.07 \pm 1.76^{\mathrm{d}}$ & $152.5 \pm 6.64^{\mathrm{b}}$ & $38.72 \pm 6.7 \mathrm{~d}$ & $99.28 \pm 6.45^{\mathrm{d}}$ & $16.41 \pm 0.35^{\mathrm{b}}$ \\
Vitamin E & $21.08 \pm 0.6^{\mathrm{b}}$ & $29.9 \pm 1.71^{\mathrm{b}}$ & $186.8 \pm 15.5 \mathrm{~b}$ & $161.12 \pm 14.9^{\mathrm{c}}$ & $4.21 \pm 0.13^{\mathrm{b}}$ \\
\hline
\end{tabular}

HDL- High density lipoprotein; LDL- Low density lipoprotein; VLDL- Very low density lipoprotein; PEFPetroleum ether fraction; CF- Chloroform fraction; EAF- Ethylacetate fraction; RF- Residual fraction. Values are expressed as mean $\pm \mathrm{SEM} ; \mathrm{n}=6$ in each group $\mathrm{P}<0.01$ when compared to normal control, $\mathrm{b}<<0.01, \mathrm{P}<0.05$ and $\mathrm{d} P<0.05$ when compared to alcohol control (one way ANOVA followed by Dunnett's test)

The activities of enzymatic antioxidants like SOD, CAT, Px, GPx and GSSH in brain tissue of rats fed with ethanol were significantly $(P<0.01)$ lower when compared with control rats. Rats fed with the PEF, EAF and CF of $V$. negundo and vitamin E displayed increased activities as compared to ethanol-fed rats. Rats treated with the RF did not show a significant increase $(P>0.05)$ in the activities of the above enzymes (Table 4$)$. 
Table 3: Effect of fractions of $V$. negundo on brain tissue protein, MDA and LH in control and experimental animals

\begin{tabular}{llll}
\hline Treatment & Protein & MDA & LH \\
\hline Normal control & $3666.6 \pm 149$ & $0.175 \pm 0.01$ & $0.55 \pm 0.06$ \\
Alcohol control & $1750.8 \pm 668 \mathrm{a}$ & $2.035 \pm 0.35^{\mathrm{a}}$ & $5.24 \pm 0.9^{\mathrm{a}}$ \\
PEF & $1767 \pm 195.0 \mathrm{~b}$ & $0.9 \pm 0.08^{\mathrm{b}}$ & $1.48 \pm 0.12^{\mathrm{b}}$ \\
CF & $2083.8 \pm 61 \mathrm{~b}$ & $0.6 \pm 0.08^{\mathrm{b}}$ & $1.35 \pm 0.05^{\mathrm{b}}$ \\
EAF & $1719 \pm 171 \mathrm{~b}$ & $0.8 \pm 0.06^{\mathrm{b}}$ & $1.56 \pm 0.23^{\mathrm{b}}$ \\
RF & $1762 \pm 179 \mathrm{~b}$ & $1.25 \pm 0.01^{\mathrm{b}}$ & $1.84 \pm 0.11^{\mathrm{b}}$ \\
Vitamin E & $3638.8 \pm 25 \mathrm{~b}$ & $0.25 \pm 0.018^{\mathrm{b}}$ & $0.7 \pm 0.03^{\mathrm{b}}$ \\
\hline
\end{tabular}

Protein (mmoles/min/mg wet tissue), MDA - Malondialdehyde (nmoles/min/mg protein), LH - Lipid hydroperoxides (nmoles/min/mg protein), PEF - Petroleum ether fraction, CF - Chloroform fraction, EAF Ethylacetate fraction, RF - Residual fraction. Values are expressed as mean $\pm \mathrm{SEM} ; \mathrm{n}=6$. ${ }^{\mathrm{P}}<0.01$ when compared to normal control ${ }^{b} \mathrm{P}<0.01$ when compared to alcohol control (one way ANOVA followed by Dunnett's test)

Rats fed with ethanol showed a significant $(P<0.01)$ reduction in the concentrations of GSH and $\alpha$-tocopherol when compared to normal rats. Rats fed simultaneously with ethanol and the PEF, EAF and CF of $V$. negundo showed a significant $(P<0.01)$ elevation in GSH and $\alpha$ tocopherol. This effect was almost similar to the vitamin $\mathrm{E}$ treated rats. Rats treated with RF did not show a significant increase $(P>0.05)$ in the levels of non-enzymatic antioxidants (Table 5).

Table 4: Effect of fractions of V. negundo on brain tissue enzymatic antioxidants in control and experimental animals

\begin{tabular}{llllll}
\hline Treatment & CAT & GPx & SOD & GSSH & Px \\
\hline Normal control & $29.4 \pm 1.3$ & $43.4 \pm 1.23$ & $27.1 \pm 1.45$ & $19.6 \pm 1.45$ & $33.5 \pm 1.1$ \\
Alcohol control & $13.5 \pm 2.7^{\mathrm{a}}$ & $32.7 \pm 4.44^{\mathrm{a}}$ & $10.88 \pm 1.5^{\mathrm{a}}$ & $9.1 \pm 1.8^{\mathrm{a}}$ & $9.9 \pm 1.5^{\mathrm{a}}$ \\
PEF & $20.3 \pm 1.3^{\mathrm{a}}$ & $42.79 \pm 2.0^{\mathrm{b}}$ & $20.8 \pm 3.2^{\mathrm{c}}$ & $14.9 \pm 1.6^{\mathrm{c}}$ & $19.5 \pm 1.9^{\mathrm{c}}$ \\
CF & $23.0 \pm 3.1^{\mathrm{c}}$ & $41.0 \pm 2.50^{\mathrm{b}}$ & $22.17 \pm 3.1^{\mathrm{c}}$ & $18.3 \pm 1.3^{\mathrm{b}}$ & $29.2 \pm 4.9^{\mathrm{b}}$ \\
EAF & $19.5 \pm 1.1^{\mathrm{d}}$ & $39.75 \pm 2.3^{\mathrm{d}}$ & $19.1 \pm 1.3^{\mathrm{d}}$ & $15.23 \pm 1.4^{\mathrm{c}}$ & $17.5 \pm 2.8^{\mathrm{d}}$ \\
RF & $15.9 \pm 0.5^{\mathrm{d}}$ & $34.2 \pm 2.0^{\mathrm{d}}$ & $17.2 \pm 0.6^{\mathrm{d}}$ & $13.7 \pm 0.6^{\mathrm{a}}$ & $15.6 \pm 1.1^{\mathrm{d}}$ \\
Vitamin E $^{\text {Citam }}$ & $29.0 \pm 0.7^{\mathrm{b}}$ & $41.9 \pm 0.5^{\mathrm{b}}$ & $26.3 \pm 0.5^{\mathrm{b}}$ & $18.6 \pm 0.3^{\mathrm{b}}$ & $31.9 \pm 0.6^{\mathrm{b}}$ \\
\hline
\end{tabular}

CAT- Catalase ( $\mu$ moles/mg protein); GPx- Glutahione peroxidase (nmoles/min/mg protein); SOD- Superoxide dismutase (nmoles/min/mg protein); GSSH- Glutathione reductase (nmoles/min/mg protein); Px- Peroxidase (nmoles/min/mg protein); PEF- Petroleum ether fraction; CF- Chloroform fraction; EAF - Ethylacetate fraction; RF- Residual fraction. Values are mean $\pm \mathrm{SEM} ; \mathrm{n}=6$. ${ }^{\mathrm{a}} \mathrm{P}<0.01$ when compared to normal control ${ }^{\mathrm{b}} \mathrm{P}<0.01, \mathrm{cP}<$ 0.05 and $\mathrm{P}>0.05$ when compared against alcohol control (one way ANOVA followed by Dunnett's test).

Table 5: Effect of fractions of Vitex negundo on brain tissue non-enzymatic antioxidants in control and experimental animals

\begin{tabular}{lll}
\hline Treatment & GSH & $\boldsymbol{\alpha}$-tocopherol \\
\hline Normal control & $35.3 \pm 0.9$ & $5.3 \pm 0.1$ \\
Alcohol control & $17.6 \pm 3.6^{\mathrm{a}}$ & $3.1 \pm 0.1^{\mathrm{a}}$ \\
PEF & $34.0 \pm 2.2^{\mathrm{b}}$ & $4.4 \pm 0.2^{\mathrm{b}}$ \\
CF & $33.6 \pm 1.3^{\mathrm{b}}$ & $5.0 \pm 0.1^{\mathrm{b}}$ \\
EAF & $32.8 \pm 3.6^{\mathrm{c}}$ & $3.4 \pm 0.1^{\mathrm{d}}$ \\
RF & $22.9 \pm 1.4^{\mathrm{d}}$ & $3.1 \pm 0.1^{\mathrm{d}}$ \\
Vitamin E & $34.6 \pm 0.3^{\mathrm{b}}$ & $5.3 \pm 0.1^{\mathrm{b}}$ \\
\hline
\end{tabular}

Values are expressed as mean \pm SEM; $\mathrm{n}=6$ in each group. ${ }^{\mathrm{a}} \mathrm{P}<0.01$ when compared to normal control ${ }^{\mathrm{b}} \mathrm{P}<0.01$, $c \mathrm{P}<0.05$ and $\mathrm{d} P>0.05$ when compared to alcohol control (one way ANOVA followed by Dunnett's test). 
The results of the histopathological studies are presented in Figures 1-7. Section of the brain tissue of control rats showed normal brain architecture with glial tissue (Figure 1). The brain section of alcohol-fed rats showed profound gliosis and there is no evidence of necrosis (Figure 2). On the other hand, rats treated with the PEF, EAF and CF of V. negundo showed normal glial tissue with minimal gliosis (Figures 3-5). Rats treated with the RF did not reverse the gliosis produced by ethanol (Figure 6). Rats treated with vitamin E showed normal architecture of brain and no gliosis, which is almost similar to the control rats (Figure 7).
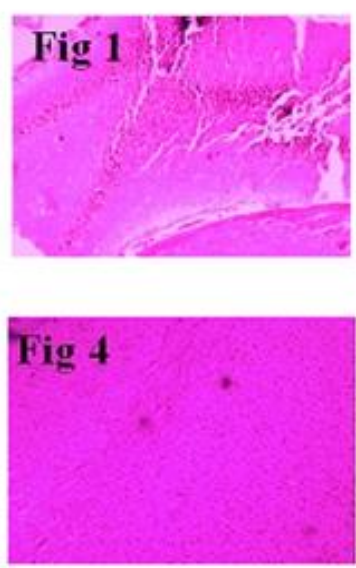
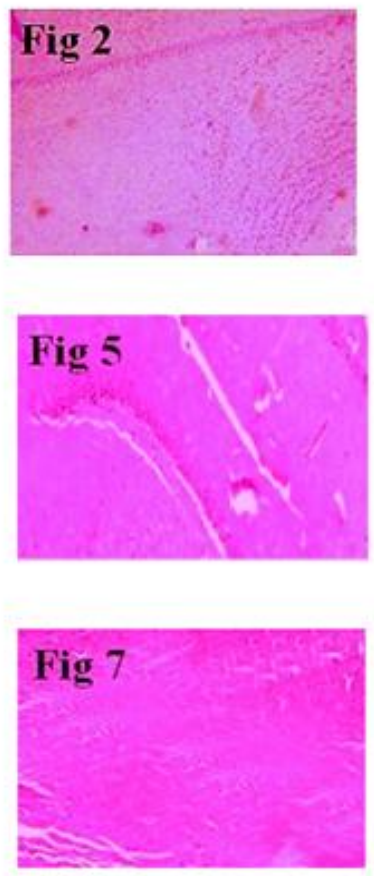
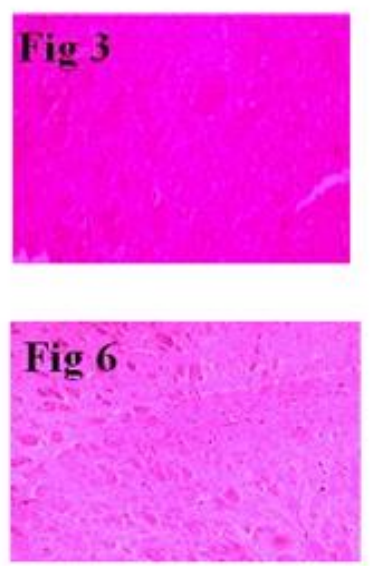

Figures 1-7: Histopathological brain sections of control and experimental animals

Control rats with normal brain architecture (Fig 1); brain section of alcohol-fed rats with profound gliosis (Fig 2); brain tissue of rats treated with the PEF, EAF and CF of $V$. negundo with normal glial tissue and minimal gliosis (Figures 3-5); rats treated with the RF did not reverse the gliosis produced by ethanol (Fig 6); rats treated with vitamin $\mathrm{E}$ with normal architecture of brain and no gliosis (Fig 7).

\section{Discussion}

Rats fed with ethanol showed a reduction in body weight due to the reduced body fat mass and reduction of adipose tissue (Das \& Vasudevan, 2005). It might be possible that the ethanol-fed rats were malnourished (Velvizhi et al., 2002). Rats treated with the various fractions of $V$. negundo showed significant weight gain, which indicates that it attenuated the malnutrition.

The elevated activities of AST, ALT and ALP in the serum of ethanol-fed rats indicate mitochondrial injury (Cohen, 1970). Ethanol-induced elevation in the levels of serum lipids may be due to an imbalance between the synthesis and degradation of lipids by the liver, which is the main cause for atherosclerotic heart disease (Sen \& Mukherjee, 1997; Navder et al., 1999). Rats fed with ethanol showed hypertriglyceridemia, which is due to the reduced 
activity of the enzyme lipoprotein lipase and triglyceride lipase thus resulting in the decreased uptake of triglycerides from serum and an accumulation in the tissues (Parker et al., 1990). Ethanol administration showed an elevation in the levels of cholesterol due to the increased activity of the enzyme $\beta$-hydroxymethylglutaryl CoA (HMG CoA) which catalyses the rate limiting step in cholesterol biosynthesis leading to increased cholesterol synthesis in tissues and excess cholesterol leaking out into the blood (Ashakumary \& Vijayammal, 1993). Metabolism of ethanol to acetaldehyde leads to the conversion of a portion of tissue xanthine dehydrogenase $(\mathrm{XDH})$ to xanthine oxidase $(\mathrm{XO})$, causing an elevation in serum uric acid level. Likewise conversion might occur due to an increase in cellular NADH as a result of ethanol oxidation with subsequent production of superoxide anion radicals, which could contribute to the enhancement of uric acid (Sultatos, 1988). In the present study, rats fed with ethanol produced a significant increase in serum uric acid level and co-administration of the fractions of $V$. negundo and vitamin E reversed the effect produced by ethanol.

Easily peroxidizable fatty acids present in high concentrations in brain are the reason for the elevated levels of MDA and LH due to ethanol administration. Ethanol induces lipid peroxidation through iron that is present in certain regions of brain which catalyses the generation of oxygen derived free radicals (Nistico et al., 1992). Hydroxyethyl free radicals from ethanol having long half life produce damage to the membrane due to an increase in lipid peroxidation (Guochuan et al., 1998). MDA and LH are the end products of lipid peroxidation whose levels were elevated in the brain, kidney, liver and heart of the ethanoltreated rats (Jaya et al., 1993). We observed a significant reduction in the levels of MDA and LH in the brain tissue of rats receiving ethanol simultaneously with the fractions of $V$. negundo, thus showing the beneficial effect of the fractions against ethanol-induced toxicity.

Increased lipid peroxidation causes a decrease in cellular defense system. The activity of enzymatic antioxidants has been decreased in ethanol-fed rats. Superoxide anion radical produces damage to the membranes and biological structures that is protected by SOD. Inhibition of activity of SOD results in the generation of partially reduced oxygen species. When SOD activity is decreased, neurons are more vulnerable to oxyradical injury (Guochuan et al., 1998).

The decomposition of $\mathrm{H}_{2} \mathrm{O}_{2}$ to $\mathrm{H}_{2} \mathrm{O}$ is catalysed by CAT in association with GPx. Thus, a decrease in the activities of the above enzymes leads to an accumulation of $\mathrm{H}_{2} \mathrm{O}_{2}$ in the tissues. Also a decrease in the activity of GSSH occurs due to the depletion of thiol groups, leading to related pathologies (Scapagnini et al., 2002). Administration of the fractions of $V$. negundo minimized the effect of ethanol-induced decrease in enzymatic antioxidants.

Decrease in the levels of non-enzymatic antioxidants like GSH and $\alpha$-tocopherol in ethanol-fed rats were due to an inhibition in their protective effect against lipid peroxidation. Oxidative stress occurs due to the accumulation of oxidized glutathione (GSSG), which is due to the inability of GSH to maintain the redox state. A decrease in the GSH level results from the binding of acetaldehyde to the cysteine residues in GSH (ElSokkary et al., 1999). Also, the cellular level of $\alpha$-tocopherol is maintained by GSH by neutralizing the free radicals (Winkler, 1992). Treatment of rats with the fractions of $V$. negundo and vitamin $\mathrm{E}$ inhibited the decrease in non-enzymatic antioxidant levels.

Rats fed with ethanol produced gliosis in brain tissue. Treatment with the PEF, CF and EAF of $V$. negundo reduced gliosis in brain tissues. These observations revealed that the fractions exhibited significant protection against ethanol-induced cerebral toxicity. 
Vitamin E prevented ethanol-induced toxicity in rat brain. Supplementation with antioxidant such as vitamin $\mathrm{E}$ has been reported to be useful in the prevention of alcoholinduced neural disorders (Agar et al., 2003). The leaves of $V$. negundo have been reported to possess flavonoids, alkaloids, terpenoids and tannins (Singh et al., 1999). These phytochemical constituents are reported to possess antioxidant properties and have shown to be potent inhibitors of lipid peroxidation. The chloroform fraction exhibited highest antioxidant activity and significantly inhibited lipid peroxidation and the activity is almost comparable to the effect of the standard drug vitamin $\mathrm{E}$.

In conclusion, the results obtained from the present study provide a rationale for the use of the leaves of $V$. negundo for the treatment of alcohol-related disorders. Studies are presently undertaken in our laboratory to isolate and characterize the active ingredients from the leaves.

\section{References}

Alam, M.I. \& Gomes, A. (2003) Snake venom neutralization by Indian medicinal plants root extracts. Journal of Ethnopharmacology 86, 75-80.

Ashakumary, L. \& Vijayammal, P.L. (1993) Additive effect of alcohol and nicotine on lipid metabolism in rats. Indian Journal of Experimental Biology 31, 270-274.

Avadhoot, Y. \& Rana, A.C. (1991) Hepatoprotective effect of Vitex negundo against carbon tetrachloride-induced liver damage. Archives of Pharmacological Research 14, 96-98.

Baker, H., Frank, O., DeAngelis, B. \& Feingold, S. (1980) Plasma tocopherol in man at various times after ingesting fee or acetylated tocopherol. Nutrition Reports International 21, 531-536.

Callaway, J.K., Beart, P.M. \& Jarrott, B. (1998) Available procedure for comparison of antioxidants in rat brain homogenates. Journal of Pharmacological and Toxicological Methods 39, 155-162.

Charness, M.E., Simon, R.P. \& Greenberg, D.A. (1989) Ethanol and the nervous system. New England Journal of Medicine 321, 442-454.

Cohen, S. (1970) Phosphatase. In: A. Lajtha (ed.), Handbook of Neurochemistry. Plenum Press, pp. 87-131.

Das, S.K. \& Vasudevan, D.M. (2005) Effect of ethanol on liver antioxidant defense system: a dose dependent study. Indian Journal of Clinical Biochemistry 20, 79-83.

Das, S.K., Hiran, K.R., Mukhrejee, S. \& Vasudevan, D.M. (2007) Oxidative stress is the primary event, effects of ethanol consumption in brain. Indian Journal of Clinical Biochemistry 22, 99-104.

Dharmasiri, M.G., Jayakody, J.R., Galhena, G., Liyanage, S.S. \& Ratnasooriya, W.D. (2003) Anti-inflammatory and analgesic activities of mature fresh leaves of Vitex negundo. Journal of Ethnopharmacology 87, 199-206.

Dianzani, M.U. (1985) Lipid peroxidation in ethanol poisoning; a critical reconsideration. Alcohol and Alcoholism 20, 161-173.

Ellman, G.L. (1959) The sulphydryl groups. Archives of Biochemistry and Biophysics 32, 70-77.

El-Sokkary, G.H., Reiter, J.R., Tan, D., Kim, S.J. \& Cabrera, J. (1999) Inhibitory effect of melatonin on products of lipid peroxidation resulting from chronic ethanol administration. Alcohol and Alcoholism 34, 842-850. 
Guochuan, E.T., Ragan, P., Chang, B.S.R., Chen, B.S.S., Markku, V., Linnoila, I. \& Coyle, T. (1998) Increase glutamatergic neurotransmissions and oxidative stress after alcohol withdrawal. The American Journal of Psychiatry 155, 726-732.

Gupta, M., Mazumdar, U.K. \& Bhawal, S.R. (1999) CNS activity of Vitex negundo Linn. in mice. Indian Journal of Experimental Biology 37, 143-146.

Halliwell, B. \& Gutteridge, J.M.C. (1989) Free Radicals in Biology and Medicine. Oxford, Clarendon Press, pp. 573-575.

Jaya, D.S., Augstin, J. \& Venugopal, P.M. (1993) Role of lipid peroxides, glutathione and antiperoxidative enzymes in alcohol and drug toxicity. Indian Journal of Experimental Biology 31, 453-459.

Kakkar, P., Das, B. \& Viswanathan, P.N. (1984) A modified spectrophotometric assay of superoxide dismutase. Indian Journal of Biochemistry and Biophysics 21, 130-132.

Lobarzewski J, Ginalska J (1995) Industrial use of soluble or immobilized plant peroxidase. Plant Peroxidase Newsletter 6, 3-7.

Lowry, O.H., Rosenbourgh, N.J., Farr, A.L. \& Randall, R.J. (1951) Protein measurement with Folin phenol reagent. The Journal of Biological Chemistry 193, 265-275.

Matsuzaki, S. \& Lieber, C.S. (1977) Increased susceptibility of hepatic mitochondria to the toxicity of acetaldehyde after chronic ethanol consumption. Biochemical and Biophysical Research Communications 75, 1059-1065.

Navder, K.P., Baroana, E., Leo, M.A. \& Lieber, C.S. (1999) Oxidation of LDL in baboons is increased by alcohol and attenuated by polyenylphosphatidylcholine. Journal of Lipid Research 40, 983-987.

Niehaus, W. G. \& Samuelsson, B. (1968) Formation of malondialdehyde from phospholipids arachidonate during microsomal lipid peroxidation. European Journal of Biochemistry 6, 126-130.

Nistico, G., Cirilol, H.R., Fiskin, K., Lannone, M., Martino, A. \& Rohilio, G. (1992) NGF restores decrease in catalase activity and increases superoxide dismutase and glutathine peroxidase activity in the brain of aged rats. Free Radical Biology and Medicine 12, 177-181.

Nordman, R., Ribiere, C. \& Rouach, H. (1990) Ethanol-induced lipid peroxidation and oxidative stress in extrahepatic tissues. Alcohol and Alcoholism 25, 231-237.

Nordmann, R. (1994) Alcohol and antioxidant systems. Alcohol and Alcoholism 29, 513-522.

Paglia, D.E. \& Valentine, W.N. (1967) Studies on the quantitative and qualitative characterization of erythrocyte glutathione peroxides. The Journal of Laboratory and Clinical Medicine 70, 158-159.

Parker, J.G., Auerbach, W. \& Goldberg, D.M. (1990) Effect of alcohol on lipoprotein metabolism. Enzyme 43, 47-55.

Phillips, G.B., Victor, M., Adams, R.D. \& Davidson, C.S. (1952) The Journal of Clinical Investigation 31, 859-871.

Racker, E. (1995) Enzymatic synthesis and breakdown of desoxyribose phosphate. The Journal of Biological Chemistry 217, 885.

Saravanan, R, Prasad, N.R. \& Pugalendi, K.V. (2003) Effect of Piper betel leaf extract on alcoholic toxicity in the rat brain. Journal of Medicinal Food 6,261-265.

Scapangnini, G., Ravagna, A., Bella, R., Colombrita, C., Pennisi, G., Calvani, M., Alkon, D. \& Calabrese, V. (2002) Long-term ethanol administration enhances age-dependent modulation of redox state in brain and peripheral organs of rat, protection by acetylcarnitine. International Journal of Tissue Reactions 24, 89-96. 
Scheepers, B.D. (1997) Alcohol and the brain. British Journal of Hospital Medicine 57, 548-551.

Sen, S. \& Mukherjee, S. (1997) Interrelationship of dietary lipids and ascorbic acid with hepatic enzymes of cholesterol metabolic pathway. Indian Journal of Experimental Biology 35, 42-45.

Singh, V., Dayal, R. \& Bartley, J.P. (1999) Volatile constituents of Vitex negundo leaves. Planta Medica 65, 580-582.

Sinha, A.K. (1972) Colorimetric assay of catalase. Analytical Biochemistry 47, 389-394

Sultatos, L. G. (1988) Effects of acute ethanol administration on the hepatic xanthine dehydrogenase/oxidase system in the rats. The Journal of Pharmacology and Experimental Therapeutics 246, 946-949.

Tandon, V.R. \& Gupta, R.K. (2006) Vitex negundo Linn leaf extract as an adjuvant therapy to standard anti-inflammatory drugs. The Indian Journal of Medical Research 124, 447-450

Velvizhi, S., Nagalashmi, I., Essa, M.M., Dakshayani, K.B. \& Subramanian, P. (2002) @ketoglutarate on lipid peroxidation and antioxidant status during chronic ethanol administration in Wistar rats. Polish Journal of Pharmacology 54, 231-236.

Warrier, P.K., Nambiar, V.P.K. \& Ramankutty, C. (1995) Indian Medicinal Plants. New Delhi, Orient Longman Ltd, pp. 1937-1940.

Winkler, B.S. (1992) Unequivocal evidence in support of the non-enzymatic redox coupling between glutathione/glutathione disulfide and ascorbic acid/dehydroascorbic acid. Biochimica et Biophysica Acta - General Subjects 1117, 287-290.

Zima, T., Fialova, L., Mestek, O., Janebova, M., Crkovska, J., Malbohan, I., Stipek, S., Mikulikova, L. \& Popov, P (2001) Oxidative stress, metabolism of ethanol and alcoholrelated diseases. Journal of Biomedical Science 8, 59-70. 